\title{
Incontinência urinária e envelhecimento: impacto no cotidiano e na Qualidade de vida
}

\author{
Urinary incontinence and aging: impact on daily basis and on the Quality of life \\ Incontinencia urinaria y envejecimiento: impacto en lo cotidiano y en la calidad de vida
}

\author{
Melissa Orlandi Honório', Silvia Maria Azevedo dos Santos ${ }^{1}$ \\ 'Universidade Federal de Santa Catarina. Departamento de Enfermagem. Florianópolis, SC
}

Submissão: 12/08/2008

Aprovação: 20/12/2008

\section{RESUMO}

O envelhecimento humano vem acompanhado de um desgaste físico funcional do corpo e da mente, bem como de uma diminuição das respostas fisiológicas às ações do meio. Isto acaba por alterar a Qualidade de vida das pessoas em processo de envelhecimento, especialmente, no Que tange a independência e autonomia. Dentre as alterações comuns com o processo de envelhecimento encontramos a incontinência urinária, Que, além de possuir múltiplas etiologias com grande complexidade terapêutica, gera um enorme impacto sobre a Qualidade de vida dessas pessoas. Sendo assim, este artigo abordará um recorte da pesQuisa realizada para a dissertação de mestrado de uma das autoras, onde se buscou compreender em Que proporção a incontinência urinária atinge não só o cotidiano das pessoas Que a possuem, como também a sua Qualidade de vida, sendo esse o foco de discussão deste artigo.

Descritores: Incontinência urinária; Qualidade de vida; Envelhecimento.

\section{ABSTRACT}

Human aging is accompanied by worn out of the physical functions of body and mind as well as a decrease in physiological response to the environment. Consequently these change the euality of life for those going through the aging process, especially regarding independence and autonomy. Among these common aging changes, there is the urinary incontinence having multiple etiologies with great therapeutic complexity, which creates a huge impact on the life Quality of these people. This article will focus on part of a research done for a master's dissertation from one of the authors, which sought to understand in what proportion urinary incontinence affects, not only their daily lives but also their Quality of life.

Descriptors: Urinary incontinence; Quality of life; Aging.

\section{RESUMEN}

El envejecimiento humano viene acompañado de un desgaste físico funcional del cuerpo y de la mente, así como una disminución de las respuestas fisiológicas a las acciones del medio ambiente. Esto acaba alterando la calidad de vida de las personas en proceso de envejecimiento, especialmente, en lo que se refiere a independencia y autonomía. Entre las alteraciones más comunes en el proceso de envejecimiento, encontramos la incontinencia urinaria Que además de poseer múltiples etiologías con una gran complexidad terapéutica, genera un enorme impacto sobre la calidad de vida de esas personas. Siendo así, este artículo abordará un recorte de la investigación realizada para la disertación de maestría de una de las autoras, donde se buscó comprender en Que proporción la incontinencia urinaria alcanza no sólo a lo cotidiano de las personas Que la sufren, como también a la calidad de vida de las mismas.

Descriptores: Incontinencia urinaria; Calidad de vida; Envejecimiento. 


\section{INTRODUÇÃO}

O falar e o andar, associados ao controle vesical e intestinal, são sinais de evolução de uma criança Que está saindo da primeira infância. Costuma-se, entretanto, associar a falta de controle dos atos de urinar e de evacuar com aspectos relativos à imaturidade, infantilização, ou, pior, ao declínio e à perda de autonomia. Para muitos, a incontinência ainda possui conotações de maus hábitos de higiene e provoca mal-estar. Assim, pessoas Que sofrem desse distúrbio, especialmente se forem idosos, vivenciam essa situação apresentando problemas psicossociais, como a perda da autoestima, isolamento social e o embaraço. Sendo assim, a incontinência urinária traz ao indivíduo importantes repercussões físicas e sociais, na forma como se manifesta. Segundo conceito da International Continence Society, a incontinência urinária tratase de uma perda involuntária de urina, Que é um problema social ou higiênico ${ }^{(1)}$.

Contudo, nem todos Que posuem incontinência procuram ajuda profissional. Estima-se que uma a cada três pessoas que sofrem de incontinência sintam-se constrangidas em falar sobre o assunto com familiares, amigos ou com um profissional de saúde, fazendo com Que essas pessoas convivam com o problema por muitos anos, sem procurar ajuda, e o considerem "normal"(2). Sabe-se, no entanto, Que tais distúrbios acabam por afetar diversos aspectos da vida, não só o físico, como também o social, psicológico, ocupacional, doméstico e sexual. Muitos idosos acabam mudando sua rotina de vida diária e isolando-se. Deixam de freqüenter festas, casas de amigos e familiares; muitas vezes impedem visistas a sua própria casa, com receio de Que as pessoas percebam o odor de urina.

Mediante o Que foi exposto acima, e sabendo-se ser a incontinência urinária uma alteração não inerente ao processo de envelhecimento, porém com uma alta incidência na população de idosos, a assistência a esses pacientes constitui-se num grande desafio, que transcende o conforto e a higiene.

A rede de apoio à saúde do paciente incontinente, de maneira conservadora e não invasiva, ainda é algo deficitário em nossa região. Isto é percebido, sobretudo, devido a ausência de um serviço de enfermagem Que atenda a essa população dentro do Sistema Único de Saúde - SUS, na cidade de Florianópolis. Desta forma, a pesquisa realizada veio ao encontro de uma lacuna existente nessa área. Assim, foi desenvolvida uma pesquisa focada no autocuidado de pacientes idosos com incontinência urinária, através de um projeto piloto implementado num ambulatório do Hospital Universitário, estando este vinculado ao Núcleo Interdisciplinar de Pesquisa, Ensino e Assistência Geronto-geriátrica - NIPEG/HU/ UFSC. Assim, o autocuidado como proposta de tratamento ao paciente incontinente, traz consigo a possibilidade de melhoras com recuperação da continência a baixos custos.

Diante de inúmeros tratamentos existentes para a incontinência urinária, com o passar dos anos, muitas denominações surgiram para definir os variados tipos destes. No intuito de uniformizar as denominações, optou-se, neste trabalho, em assumir a última definição da International Continence Society divulgada em 2002, onde assume Que a reabilitação do trato urinário baixo inclui todos os tratamentos não-cirúrgicos, não farmacológicos para a função do trato urinário inferior, incluindo o treinamento do assoalho pélvico, biofeedback e mudanças comportamentais (Informações apresentadas pela Escola Paulista de Medicina, através do site http:/ /www.uroginecologia.com.br/index).

A terapia comportamental em particular, é um método não invasivo de tratamento, de baixo risco, pouco dispendioso e que pode se constituir numa estratégia de tratamento efetiva e conservadora na recuperação das funções fisiológicas, causando uma melhora da musculatura do assoalho pélvico ${ }^{(3)}$. Ela consiste em estimular modificações comportamentais e mudanças dos hábitos do cliente Que possam contribuir para piorar ou causar episódios de perdas urinárias, associando a isso um retreinamento da bexiga.

Assim, dentre as orientações necessárias, inclui-se a alteração de hábitos alimentares, como a minimização da ingesta de cafeinados, excesso de lípuidos antes de dormir, frutas ácidas, achocolatados e refrigerantes ${ }^{(4)}$. Essas mudanças devem ser estimuladas, já Que alguns desses são considerados irritantes vesicais, e poderiam, de certa forma, agravar os episódios de perdas urinárias, sobretudo nas situações de urgeincontinência ${ }^{(5)}$.

Além disto, as modificações Quanto aos hábitos intestinais são também consideradas peças fundamentais para o tratamento conservador. Isso porQue se acredita Que problemas Que impeçam um trânsito intestinal normal, como a constipação, podem contribuir para a piora da incontinência, devido ao aumento da pressão do reto sobre a bexiga ${ }^{(6)}$. Pode-se associar a isso o retreinamento da bexiga e exercícios para fortalecimento da musculatura do assoalho pélvico. Existem inúmeros exercícios possíveis Que vêm sendo realizado com êxito por diversos profissionais. Os mesmos vão desde ensinamentos da simples contração e relaxamento da musculatura do assoalho pélvico, até exercícios modificados, incluindo a alteração da posição- ortostática, sentado e decúbito dorsal- e uso de instrumentos como bolas para facilitar a realização dos $\operatorname{mesmos}^{(7)}$.

\section{METODOLOGIA}

Este estudo configura-se como uma pesQuisa Qualitativa, usando uma abordagem convergente assistencial. Na pesquisa Qualitativa, o pesquisador é capaz de participar, além de tentar compreender e interpretar os dados coletados ${ }^{(8)}$.

A pesquisa convergente-assistencial, por sua vez, procura manter a todo instante uma íntima relação com a prática assistencial, tendo como foco, a busca por alternativas e soluções aos problemas e dificuldades surgidas ${ }^{(9)}$. Para esse estudo utilizou-se como referencial teórico-metodológico a Teoria do autocuidado de Orem $^{(10)}$ e as concepções de educação propostas por Freire ${ }^{(11)}$.

Sabendo ser a mudança da realidade um dos principais objetivos Que a pesQuisa convergente-assistencial se propõe a realizar, a presente investigação mostrou-se comprometida com a abordagem adotada. Assim, o trabalho desenvolvido pôde trazer mudanças para a realidade vivenciada pelos pacientes incontinentes, Que antes não possuíam acesso a tratamentos conservadores como a terapia comportamental, através do Sistema Único de Saúde - SUS. Além disto, trouxe inovação para a assistência de enfermagem e para a instituição, mostrando sua viabilidade na prática e baixos custos.

A peseuisa, antes de ser iniciada, passou pela aprovação do Comitê de Ética em Pesquisa com Seres Humanos da UFSC. O 
local de desenvolvimento foi o ambulatório do Hospital Universitário da Universidade Federal de Santa Catarina. Participaram da mesma, Quatro sujeitos, com idades entre 50 e 72 anos. A amostra foi de conveniência, uma vez Que todos os sujeitos receberam previamente avaliação médica e foram, por sua vez, encaminhados pelos profissionais do NIPEG/HU/UFSC. Vale ressaltar que o número reduzido de participantes deveu-se, sobretudo, ao fato do tratamento conservador reQuerer um tempo maior para apresentar resultados. Geralmente, a partir de três meses de tratamento, o paciente já passa a perceber de forma mais efetiva o controle da incontinência. Isso não significa Que, antes desse tempo, ele não possa perceber melhoras.

A pesquisa desenvolvida teve como guia o processo de enfermagem baseado nos preceitos da Teoria do autocuidado associados às concepções de educação de Freire. $\mathrm{O}$ processo de enfermagem orientou a coleta de dados e o levantamento das necessidades de educação para o autocuidado. Tal coleta foi auxiliada pela implementação e aplicação de instrumentos como a entrevista semi-estruturada, formulário de avaliação da incontinência urinária, além do diário miccional. Desta forma, enfermeira e paciente puderam identificar os déficits de autocuidado e escolher as estratégias que seriam utilizadas para atender a essa demanda. Através do apoio-educação, conseguiu-se trabalhar junto com o paciente os comportamentos e atitudes necessárias para Que ele alcançasse a competência para o autocuidado.

As atividades de educação para o autocuidado puderam ser implementadas através das consultas de enfermagem individualizadas, e buscaram contemplar as necessidades de autocuidado, identificadas na etapa anterior. As atividades desenvolvidas foram programadas conforme as possibilidades e vontade do paciente, respeitando hábitos, crenças, costumes e, principalmente, o seu conhecimento prévio. Procurou-se, no entanto, despertar no adulto e no idoso a tomada de consciência e atitudes de comprometimento para com o tratamento, Que pudesse culminar na melhora da auto-estima, autonomia e recuperação da continência.

Assim, a prática educativa deu-se a todo momento, em cada encontro, durante as consultas de enfermagem. A educação esteve sempre voltada para o aprendizado de atitudes Que pudessem ser utilizadas para o autocuidado do paciente e também refletissem em melhora das perdas urinárias e, conseQüentemente da autoestima e independência. Esse aprendizado, por sua vez, aconteceu como resultado de uma construção progressiva feita pelo próprio paciente, a partir da realidade vivenciada por ele, levando em conta seus aspectos culturais e suas formas de pensar e agir.

Nesse processo educativo, o paciente pôde contar com a participação e auxílio da família, Quando julgou necessário. A enfermeira, por sua vez, portou-se como facilitadora do processo educativo, sendo capaz de auxiliá-lo a encontrar meios e a rever atitudes que pudessem vir em seu próprio benefício. As atividades educativas partiram, primordialmente, do conhecimento prévio trazido pelo paciente, concordando com a idéia de Que o processo educativo não acontece com uma simples transferência de conhecimentos $^{(11)}$. Assim, as atividades educativas, incluindo os exercícios perineais, hábitos alimentares e intestinais, foram abordadas sempre partindo do conhecimento prévio trazido pelo idoso, através de uma relação dialógica.
Vale lembrar Que a vontade do cliente, Quanto à realização dos exercícios, foi respeitada, bem como as suas condições físicas e a adeQuação dos horários para a realização das atividades programadas pelo paciente no domicílio. Quanto às mudanças de hábitos intestinais e alimentares, foram construídas, em conjunto com o cliente, alternativas conforme suas possibilidades de aQuisição e gosto alimentar.

Essas atividades educativas puderam ser facilitadas pelo uso de materiais didáticos, como cartazes com a anatomia da bexiga e/ou livros ilustrativos. Os exercícios foram demonstrados nas consultas, e puderam ser realizados em conjunto com o paciente, tendo o auxílio de alguns instrumentos, como bola plástica e bolinha de tênis. Essas estratégias foram utilizadas para facilitar a compreensão dos exercícios e, com isso, favorecer sua correta realização no domicílio.

Os pacientes puderam ser acompanhados semanalmente ou Quinzenalmente, conforme a necessidade identificada. $\mathrm{O}$ tratamento transcorreu até o momento em Que houve melhora total ou parcial das perdas urinárias, ou enQuanto houve demonstração de vontade e interesse por parte do paciente. Nessa tomada de decisão, também foi fundamental a auto-avaliação do paciente Quanto à sua satisfação com os resultados obtidos. Em alguns casos, o período de tratamento superou o período da pesquisa, não significando, porém, interrupção da assistência prestada.

Além da gravação da entrevista realizada, puderam-se realizar registros em diário de campo, logo após o término de cada consulta de enfermagem. Nesses registros, foram apontadas as observações pessoais sobre o transcurso da consulta, percepções sobre as reações dos pacientes e familiares, impressões pessoais, reflexões e sentimentos.

\section{RESULTADOS}

Tendo em vista os resultados coletados a partir das consultas realizadas, das transcrições das fitas gravadas durante os encontros, dos dados obtidos através dos instrumentos aplicados, associados às anotações feitas por mim em diário de campo, a análise dos resultados pôde ser realizada. Tal análise teve como base os princípios propostos para análise de conteúdo ${ }^{(12)}$. Dessa forma, o primeiro passo para a análise dos dados foi realizar uma leitura flutuante de todo material. Após essa leitura, os dados foram agrupados em "categorias nativas". Em cada grupo dessas categorias, buscou-se identificar as semelhanças e diferenças existentes entre as falas dos diversos participantes. Na seQüência, as categorias nativas foram renomeadas com termos Que pudessem definir o Que de mais expressivo se podia encontrar em cada grupo. Desta forma, surgiu uma nova organização para os dados coletados - as categorias nominais. Esse grupo de categorias permitiu, então, uma análise dos dados segundo afinidade e relação dos assuntos, propiciando comparar os dados da pesquisa com o Que se encontrou na literatura. Assim, este artigo trará à discussão duas categorias nominais identificadas como (a) hábitos de vida diários e (b) repercussão da incontinência urinária na Qualidade de vida.

No primeiro eixo temático foram abordados aspectos referentes aos hábitos de vida diários dos pacientes incontinentes, procurando resgatar seu Quotidiano, a maneira como vivem, alimentam-se e exercitam-se. A partir das conversas, durante as consultas de 
enfermagem, e através da leitura atenta dos textos gerados pela coleta de dados dos pacientes, aos poucos foi possível conhecer os diferentes hábitos da vida diária dos adultos e idosos atendidos. Estes, ao expressarem Questões referentes à sua rotina de vida diária, ressaltavam, na maioria das vezes, atividades cotidianas como hábitos de sono e repouso, alimentação e trabalho.

Fato merecedor de destaque, nessa situação, é Que a ocorrência das perdas urinárias não era relatada na descrição do Quotidiano desses pacientes, o que me levou a crer Que, para essas pessoas, a incontinência urinária havia sido naturalizada. Era como se ser portador de incontinência urinária fosse algo normal, Que já havia sido incorporado ao dia-a-dia das pessoas eue a possuíam. Dessa forma, o fato de perder urina acabava não sendo relatado, por já ter se tornado algo internalizado no Quotidiano desses pacientes, assim como outras atividades rotineiras, como os cuidados com a higiene, alimentação ou vestir-se. Outra possibilidade referente a essa não verbalização das perdas urinárias poderia estar relacionada ao constrangimento em falar sobre o assunto, já no primeiro encontro. A conversa com alguém desconhecido, à primeira vista poderia causar reações de vergonha e receio por parte do paciente. Assim, essa também é uma possibilidade a ser considerada.

Apesar desse tratamento dado à incontinência urinária ter sido percebido no grupo de pacientes atendidos, se extraíram algumas Questões importantes referentes aos transtornos gerados por ela. Primeiramente, observou-se Que, aos poucos, os pacientes passavam a criar estratégias para conviver melhor com as perdas urinárias. Isso vem mostrar Que, apesar de as perdas terem sido, aos poucos, inseridas no Quotidiano dessas pessoas, ainda assim eram considerados motivo de transtornos e incômodos. Nesse grupo de pacientes, percebeu-se Que a utilização de algum tipo de proteção para sair de casa era algo habitual. Essa estratégia de uso da proteção, absorvente ou forro, era considerada pelos pacientes como uma precaução, permitindo-lhes sair de casa com mais segurança.

Embora a utilização de proteção, ao sair de casa, tenha aparecido como algo comum, o mesmo não ocorria com freqüência no domicílio. Em casa, os pacientes verbalizaram não julgar necessário o uso de absorventes, sobretudo, pela facilidade encontrada na higiene ou troca de roupa, caso houvesse necessidade. A verbalização do paciente Quanto ao uso ou não de absorventes e proteções diárias, bem como a Quantidade e a freqüência das trocas fornece outras informações importantes, Que transcendem às estratégias utilizadas e aos transtornos causados a esses pacientes. Muitas vezes, o paciente não consegue expressar de forma clara e objetiva a Quantidade de perdas urinárias, dado Que é de suma importância para o tratamento. Assim, o relato e a descrição do número de absorventes ou protetores utilizados e trocados diariamente são uma forma de se extrair essas informações.

Outro aspecto importante Que a informação a respeito dos absorventes pode oferecer é um retorno de resposta ao tratamento. Muitas vezes, a percepção da melhoria e do surgimento dos primeiros resultados torna-se demorada, sendo a Quantificação e a comparação Quanto ao uso dos absorventes um bom retorno sobre a melhora dos sinais. Esse aspecto pode servir como fonte de motivação para o paciente continuar com o programa de reeducação.

Além da utilização de proteção perineal, alguns pacientes acabam encontrando outras alternativas, na tentativa de minimizar o risco de acidentes urinários. Algumas estratégias foram relatadas pelos pacientes, destacando-se as idas freqüentes ao banheiro, intervalos curtos entre as micções e o uso de roupas escuras. Associado a isto, outros pacientes chegam a ter sua vida social e atividades fora de casa prejudicadas. Isso acontece porque acabam ficando dependentes do banheiro, em suas saídas, procurando sempre estar por perto de um "ponto de apoio", caso seja necessário.

$\mathrm{Na}$ abordagem dos hábitos de vida de cada paciente atendido, incluindo lazer, atividades físicas, sociais e vida sexual, percebeuse ser de suma importância também abordar de Que forma eles se comportavam frente aos hábitos alimentares e intestinais. Essa abordagem, por sua vez, faz-se necessária, já Que influencia sobremaneira nas condições urinárias e na piora das perdas, por parte do paciente. Assim, no grupo de pacientes atendidos, ficou evidente Que, dentre os alimentos considerados irritantes vesicais, o café apareceu como um dos líeuidos mais ingeridos.

Outra Questão Que veio chamar a atenção referiu-se ao consumo hídrico diário. Sobre isso, o Que geralmente se percebe é Que grande parte das pessoas Que sofrem de incontinência urinária acaba diminuindo o volume de consumo de água, pelo receio de interferir no aumento das perdas de urina. . O Que se percebeu, no entanto, foi Que todos os pacientes atendidos demonstraram uma baixa ingesta de água, seja pelo medo de perder mais urina, pela falta de sede, pelo frio, ou por preferirem o consumo de café, no lugar da água.

Apesar do consumo excessivo de cafeinados associado à baixa ingesta hídrica ter sido evidente, o Que veio chamar a atenção foi a mudança de comportamento presenciada no decorrer das consultas. Não Que tal mudança tenha sido imposta ou exigida como parte de tratamento, porém, talvez, a percepção da melhora dos sinais de incontinência por parte dos próprios pacientes tenha sido o ponto-chave.

Assim, os pacientes tiveram autonomia para optar pela melhor alimentação a ser seguida, com a substituição dos alimentos irritantes por outros, da preferência de cada paciente. O mesmo aconteceu com relação à ingesta hídrica.

Além dos componentes alimentares Que podem vir a influenciar nas perdas urinárias, a constipação intestinal também parece ser foco de atenção. A presença de impactação fecal pode, muitas vezes, ser a causa de perdas urinárias, e a simples normalização desse problema pode vir a contribuir para a melhora dos sintomas de incontinência urinária. Apesar disto, a maioria dos pacientes atendidos relatou ter um funcionamento normal do intestino, não mencionando QualQuer relação das perdas com constipação intestinal. Com base nos hábitos de vida diários discutidos, observou-se a necessidade de compreender em Que proporção a incontinência afeta não só o cotidiano das pessoas afetadas, como também a sua Qualidade de vida.

Assim, ao avaliarmos o grupo de pacientes atendidos, a maioria apresentou sinais e sintomas de perdas por urgência. Foi possível identificar isso através de anamnese, exame físico, testes de esforço e diário miccional, realizados durante as consultas de enfermagem. Outro aspecto Que favoreceu a avaliação de cada caso foram os próprios relatos dos pacientes, onde era possível perceber os hábitos urinários e as características das perdas específicas de cada um.

$\mathrm{O}$ Que se presenciou neste estudo, é reforçado nas pesQuisas a 
respeito da incontinência urinária, já Que se acredita Que as perdas por urgência constituem-se na principal causa de incontinência urinária em pacientes idosos de ambos os sexos, cerca de $60 \%$. Ao relacionarmos os tipos de incontinência e as características das perdas urinárias à Qualidade de vida das pessoas Que as possuem, é possível compreender o impacto e transtornos gerados. Nos casos de pacientes com perdas por urgência, Que foram maioria neste estudo, foi possível perceber Que as atividades normais do dia-a-dia acabavam sendo prejudicadas.

As Queixas principais se davam em torno da dificuldade em sair de casa, pela necessidade de idas constantes ao banheiro e o medo de não chegar "a tempo". A dependência do banheiro se havia tornado algo comum para esses pacientes Que relataram a necessidade constante de encontrar um banheiro, assim que chegavam a supermercados, festas e casa de amigos, ou ainda Quando estavam desenvolvendo alguma atividade física.

Trazendo esses aspectos para uma discussão do Que é ter Qualidade de vida para o contexto do paciente com incontinência urinária, o Que se percebe é Que ainda existem poucos estudos específicos sobre o tema. No entanto, os estudos existentes são unânimes em apontar Que a incontinência urinária provoca importantes alterações na vida da pessoa acometida, sejam elas de aspecto social ou psicológico. Tais mudanças nos hábitos de vida puderam também ser percebidas no grupo de pacientes atendidos. Muitos deles referiram várias alterações nas atividades rotineiras, valendo aqui destacar a dificuldade em sair de casa ou participar de atividades sociais.

Apesar de se ter percebido a dimensão do que a incontinência pode vir a gerar na vida dessas pessoas, um fato Que chama atenção é a demora na procura por ajuda ou tratamentos. Foi possível perceber isso nessa pesquisa, no grupo de pacientes acompanhados. Eles referiram perder urina de um a Quatro anos. Isso vem reforçar o Que se discute a esse respeito, sabendo-se que, na maioria das vezes, os pacientes convivem anos com o problema, sem procurarem ajuda. Isso faz com Que elas acabem considerando a incontinência urinária como um evento "normal".

\section{CONCLUSÕES}

Primeiramente, cabe aqui avaliarmos o referencial teóricometodológico adotado. Apesar de as duas bases teóricas pertencerem a épocas e linhas diferentes, na prática, percebeu-se Que a junção de ambas foi possível. A sua complementaridade permitiu uma assistência de enfermagem voltada para o autocuidado Que transcendia a simples transferência de conhecimento com a imposição de orientações e cuidados. Ao contrário, a inclusão das contribuições da educação participativa, possibilitou o enfermeiro a ser um facilitador neste processo. Dessa forma, juntos, enfermeira e paciente traçaram metas e decidiram o melhor caminho a ser seguido para as ações de autocuidado.

Transcendendo às Questões referentes ao tratamento implementado, esta pesquisa convergente assistencial também propiciou realizar outras reflexões. A Qualidade de vida dos pacientes com incontinência urinária foi um dos assuntos abordados, Que merece atenção. Apesar de todos os pacientes atendidos terem demonstrado a assimilação da existência das perdas urinárias, no seu cotidiano diário, ficava evidenciado em seus relatos o impacto gerado por elas em suas vidas. O isolamento social, o constrangimento e a restrição das atividades foram os aspectos mais verbalizados pelos pacientes. O Que chamou atenção é Que, apesar desses transtornos, todos os pacientes demoraram a procurar por ajuda ou tratamentos. Sugere-se aqui, Que nesse grupo atendido, isso poderia ser justificado pelo fato das perdas serem consideradas como naturais, no cotidiano desses pacientes, já oue os mesmos não relataram sobre incontinência, ao falarem de suas atividades diárias.

Contudo, ao término do tratamento, diante de uma análise reflexiva com os pacientes, se pôde perceber Que algumas mudanças puderam ser estabelecidas. Alguns pacientes iniciaram atividades físicas, entraram em grupos de idosos ou retomaram atividades Que antes estavam esquecidas. Provavelmente, a melhora sentida em relação às perdas urinárias, com o conseQüente aumento da auto-estima, tenha propiciado uma melhora na Qualidade de vida dos pacientes atendidos.

Ao concluír a pesquisa com mulheres incontinentes, foi possível afirma oue a IU provoca sentimentos de baixa auto-estima, além de interferir na vida sexual, restringir o contato social, tarefas domésticas e de trabalho ${ }^{(1)}$. Assim, percebeu-se Que o tratamento disponibilizado para esse grupo de pacientes contribuiu, sobremaneira, para eue eles retornassem suas atividades normais, possivelmente impulsionados por um sentimento de melhora da auto-estima, culminando num incremento em sua Qualidade de vida.

Desta forma, cabe resslatar Que ao avaliar as respostas obtidas com o tratamento implementado, foi possível perceber Que os resultados atenderam às expectativas. Do grupo de pacientes atendidos, a recuperação total da continência ocorreu com três pacientes e a parcial com um. Assim, é possível afirmar que o tratamento conservador através da terapia comportamental mostrou-se eficiente para esse grupo de pacientes.

Vale lembrar Que, em todas as situações, os primeiros sinais de melhora começaram a surgir já no primeiro mês de tratamento, tendo o ápice de melhora com aproximadamente 12 semanas de acompanhamento. Essa informação foi reforçada em pesquisas realizadas junto a pacientes incontinentes, já Que, em todos os estudos, ressaltam serem necessários pelo menos três meses de tratamento, para demonstrar melhora da incontinência urinária, Quando se utiliza tratamento conservador ${ }^{(13,14)}$. Faz-se importante também ressaltar Que os pacientes atendidos nesta pesQuisa continuaram os atendimentos, apesar de a coleta de dados ter-se encerrado, em função do prazo programado para o término da pesquisa.

\section{CONSIDERAÇÕES FINAIS}

Ao abordar os eixos temáticos - hábitos de vida diários, a repercussão da incontinência urinária na Qualidade de vida - não se pretendeu aQui esgotar as Questões Que circundam a incontinência urinária. Objetivou-se trazer à tona discussões importantes e momentos de reflexão acerca desse problema tão complexo e, ao mesmo tempo, tão pouco discutido pelos profissionais da saúde. Não se pretendeu com o trabalho desenvolver com os pacientes apenas mudanças fisiológicas Que culminassem na recuperação da continência urinária.

As conQuistas obtidas transcenderam esse aspecto, tendo sido 
possível despertar nos pacientes atendidos atitudes de autonomia, tomadas de consciência e mudanças de comportamento. Essas mudanças puderam contribuir significativamente para a melhoria da Qualidade de vida dos pacientes, sendo este um importante diferencial da assistência prestada. Dessa forma, conclui-se que a peseuisa conseguiu de fato alcançar seus objetivos na totalidade, mostrando ser a urologia um campo possível para participação do enfermeiro. Além disso, mostrou Que a assistência de enfermagem é capaz de ser inovadora e participativa, na medida em Que permite Que os pacientes sejam ativos nos processos de cuidado.

\section{REFERÊNCIAS}

I. Lopes MHB, Higa R. Restrições causadas pela incontinência urinária à vida da mulher. Rev Escola Enferm USP 2006; 40(1): 34-41.

2. Shaw P. Incontinência urinária. Med Update 2003; I (I): 812.

3. Santarosa RP, Kaplan SA. Incontinência urinária de esforço em mulheres. I Bras Urol 1997; 23(2): 6I-8

4. Moreno AL. Fisioterapia em uroginecologia. São Paulo: Manole; 2004.

5. Grosse D, Sengler J. Reeducação perineal. São Paulo: Manole; 2002.

6. Rigdby M. D. Regaining continence after radical prostatectomy. Nurs Stand 2003; 18(8): 39-43.

7. Honório GS. Protocolo conservador fisioterapêutico: uma alternativa de tratamento ao homem incontinente após prostatectomia [monografia]. Florianópolis: Colégio Brasileiro de Estudos Sistêmicos; 2005.

8. Chizzotti A. Pesquisa em ciências humanas e sociais. São Paulo: Cortez; 1991.

9. Trentini M, Paim L. Pesquisa Convergente-assistencial: um desenho Que une o fazer e o pensar na prática assistencial em saúde-enfermagem. $2^{a}$ ed. Florianópolis: Insular; 2004.

10. Orem DE. Nursing: concepts of practice. $4^{\text {th }}$ ed. Saint Louis: Mosby; 1991.

11. Freire P. Pedagogia do oprimido. $17^{\mathrm{a}}$ ed. Rio de Janeiro: Paz e Terra; 1987

12. Bardin L. Análise de conteúdo. Lisboa: Edições 70; 1977.

13. Brandt FT, AlbueuerQue CDC. Eletroestimulação no tratamento alternativo da incontinência urinária feminina. I Bras Ginecol 1995; 105(1 I/I2): 50I-3.

14. Camargo ALM. Cinesioterapia do assoalho pélvico em mulheres com incontinência urinária de esforço [dissertação] São Paulo: Universidade Federal de São Paulo; 2000. 